solution in a beaker to small bulk, or better still until there is an incipient formation of crystals.

By slow cooling, as before, clusters of beautiful red thombic needles are produced. Pour off the mother liquor and dry the crystals on filter paper.

The yield averages about twenty-five per cent. by weight of the ferrocyanide used. In one experiment, the writer obtained seventeen grams of the nitroprusside from sixty grams ferrocyanide, or over twenty-eight per cent. yield. Very little is gained by treating the mother liquors for an extra yield, especially in the case of small amounts.

Sodium nitroprusside $\left(\mathrm{Na}_{8} \mathrm{Fe}(\mathrm{NO}) \mathrm{Cy}_{6}+2 \mathrm{H}_{2} \mathrm{O}\right)$ has no melting point. When heated in a glass tube, the crystal gives off moisture and becomes black without disintegration. It is slowly soluble in cold water, but easily soluble in hot water. It is best known as a very delicate reagent for sulphur in the form of alkaline sulphides, producing violet colored solutions which gradually lose color on standing.

Certain organic compounds also react with sodium nitroprusside. For instance, with a weak aqueous solution of nitroprus. side made slightly alkaline with caustic soda, formaldehyde gradually produces a dark amber tint; acetic aldehyde gives a blood-red color, becoming darker on standing, and finally violet after two or three hours; acetone produces a blood-red solution fading gradually to orange-red; and benzaldehyde gives 110 coloration.

\title{
IMPROVEMENTS IN THE COLORIMETRIC TEST FOR COPPER.
}

\author{
BY GEORGE, I, HEATH.
}

Received November 9, 5896 .

THE modifications of Heine's " blue test" described in some provement in speed of operation, ease of manipulation (in presence of the large amounts of iron, alumina and silica in poor slags or tailings), and finally in the making of the standard colors from solution of pure copper.

Having made a study of the process, and having had it in use

1 Furman's Manual of Practical Assaying, 1895, p. 159; Kerl's Metallurgy of Copper; Peter's Modern Copper Smelting, 7895, p. 65 . 
several years at a large smelting works, modifications have been adopted which certainly present a few advantages, and a full description may be of interest to those who have occasion to use the test in technical work.

It is one of those tests where the principle is a very simple one, $i . e$., the matching of colors of ammoniacal solutions of pure copper, but in which any improvement wust be made in the small, but important, details of operation.

Copper has usually to be determined in tailings or lean blast furnace slags, and must be separated from silica, and oxides of iron, alumina, and lime.

The best conditions for effecting a complete separation have been made the subject of experiments detailed in this paper. The first authority quoted directs that " a standard of pure copper should be run with each set of assays, as the color fades on standing." That is true of standards made according to Furman's Manual, but it is possible to make color standards of ammoniacal solution of pure copper, which are very permanent, having been kept for a year without alteration. Stability of color may be secured if the following facts concerning the behavior of ammoniacal copper solutions be understood and applied.

It is easily proved that if ammonia be added to a very dilute solution of nitrate, or better, the sulphate of copper, until the basic salt redissolves in excess of alkali, the color produced is first purple, then purplish-blue, and finally with a large excess of ammonia, a clear and more permanent blue.

The blue color may then incline to greenish, if there is any organic matter in the reagents or substance analyzed, for a trace of organic matter in solution is apt to prevent the complete precipitation of ferric oxide by ammonia, and the trace yet dissolved, produces a greenish tint in the ammoniacal copper solution.

The color of standards for "blue tests" is found to be very permanent, (I) if the nitric acid used to dissolve the copper be replaced by sulphuric, (2) if the excess of ammonia be sufficient to produce the clear, neutral blue, and (3) if the color standards be kept in colorless glass bottles with very tightly fitting glass stoppers, preventing the slightest evaporation or loss of ammonia. 
DIRECTIONS FOR PERMANENT STANDARDS.

Weigh a little over three-tenths gram of pure copper, place it in a flask or tall, narrow beaker, and dissolve it in five cc. of C. P. nitric acid (sp. gr. I.40) and five cc. of sulphuric acid (sp. gr. r.84). Evaporate carefully until the latter begins to evolve white fumes, and then cool, add twenty-five cc. of distilled water, and strong ammonia in sufficient excess to produce a clear solution again.

Prepare at least three liters of dilute ammonia (one volume to six parts by volume of distilled water) and dilute the copper with this until one cc. of the liquid contains exactly 0.0025 gram of pure copper, since two and a half grams of substance are always taken as a basis, and the degree of dilution then permits the whole range of colors to be made and diluted to a standard volume of $200 \mathrm{cc}$.

Measure accurately the portions of standard solution required for a set of colors, from O.IO to I.3O per cent. copper and make each one up to $200 \mathrm{cc}$. with the dilute ammonia. By this means a uniform tint and gradation of color is secured throughout the series.
The standards are kept in tall cylindrical bot-
tles of thin, colorless glass, provided with accu-
rately ground glass stoppers and having a mark on
the side at $200 \mathrm{cc}$. They must be of strictly uni-
form thickness and diameter; the dimensions for
a convenient size are shown in the sketch. (Extra
bottles for the analyses might be provided with a
stop-cock, as in a Hehner's colorimeter.) Screw
the stoppers in very tightly, mix by shaking, and
keep in a rather cool place, protected from direct
sunlight.
With the exception of one bottle, whose stopper
had become loose a few days ago, a set of such
standards bottled January I, I 896 , do not differ
from freshly prepared solutions of pure copper.
(Refer to Experiments I and 2 ). The color of the
one mentioned was remedied by filling to the mark
with a few drops of strong ammonia. 
ANALYSIS OF LEAN CUPRIFEROUS MATERIAL.

Crush and reduce the sample until the final portion, sufficient for analysis, will pass a one-hundred mesh sieve. If any pellets remain on the sieve, they should be weighed and determined separately.

It is considered better to take for analysis two and a half grams (or of material over one and two-tenths per cent., I.25 grams) rather than one-half gram, as prescribed by some writers, since the decomposition is fully as rapid, and an occasional fine particle of metal, or difference in sampling, will introduce less error in the calculated percentage. If, however, only one-half gram should be taken, this test could be used with material containing nearly six per cent. copper. The method finds its best application between zero and two per cent.

Place the weighed sample in a No. 4 porcelain casserole four and a quarter inches in diameter at the top; barely moisten it with water to prevent caking, then add fifteen cc. of nitric acid (sp. gr. I.42), and warm gently over a wire gauze until the covered dish is filled with red fumes, but not long enough to evaporate the acid. Remove, stir the mass, and break up any clots which may adhere to the dish.

When the decomposition appears to be complete, or all the copper dissolved, add five cc. of sulphuric acid (sp. gr. I.84), place the covered casserole on a wire gauze or plate, and boil tuntil the nitric acid is nearly driven off, and the mass has become a thick, but rather soft, paste. This insures the dehydration of the silica, and the change of copper to sulphate. From this point onward three practical modes of procedure are recognized, the choice of which depends on the judgment of the analyst, who may perform the following tests :

I. A working test, approximate, involving one precipitation of iron and alumina by ammonia and separation of the copper by filtration, and washing.

2. An accurate test, involving the previous separation of copper from the acid solution by reduction with aluminum. (See text-books.)

3. By the author's plan of a double precipitation by ammonia, which is sufficiently accurate and much more rapid than the second alternative plan, as will be evident from a later description. 
I. To complete the working test, cool the residue in the casserole somewhat, add $\mathrm{I} 20 \mathrm{cc}$. of water, washing the glass cover, stir well, heat until quite warm to the hand, and then add quickly enough ammonia (sp. gr. o.9) to precipitate iron and alumina, and cause the liquid to smell very strongly.

Filter, with the aid of a pump, through a fifteen cm. German filter into one of the glass bottles, and wash the precipitate by repeated additions of dilute ammonia ( 1 : IO) until the bottle is filled to the mark, allowing each portion to run through before the next is added. When the mark is reached, allow ten cc. of washings to run into a tube placed against a white paper, and if no color is detected the washing is finished.

A thorough stirring of the precipitate with a rod after each addition of wash water is essential to the most complete extraction of copper. If the slag or tailings contain less than one per cent. of copper, the extraction is sufficiently complete for approximate working tests. (Refer to the appended table of experiments.)

In the presence of a large percentage, twenty-five per cent. or more, of oxides of iron and aluminum, the copper retained in the precipitate may be considerable, if the working is faulty, but will not generally run over 0.05 per cent. This error is, in the long run, pretty nearly balanced by the tendency to read the colors too high if the shade reaches to greenish-blue instead of blue. A purplish tint in the filtrate indicates, however, that sufficient ammonia was not adcied to effect the most complete separation of copper.

If this purplish tint in the blue is very pronounced an assay should be repeated, but if slight it may be remedied by the addition of ammonia, for which allowance is made by calculation in taking the color reading.

II. Accurate Method. The copper may be separated from the major part of the basic oxides by adding thirty cc. of water and five $c c$. of stulphuric acid to the decomposed slag in casserole, then adding a piece of aluminum (one inch square and one-sixteenth of an inch thick), and boiling gently till the copper is reduced.

Remove the aluminum to a beaker, filter the solution, and wash once. Then dissolve any particles of copper from the altminum with hot dilute nitric acid (one part acid to two of water), 
transfer as much as possible of the precipitate to the casserole, and pour the acid solution from the beaker through the filter, allowing the liquid to run into the casserole. After the copper is dissolved from the filter add three cc. of sulphuric acid, cover the casserole, and boil down with a moderate heat to remove nitric acid.

Finally, precipitate by ammonia, filter, and wash as usual. This, however, offers more chances for error, and is certainly less simple and rapid than the third alternative method proposed (that of double precipitation), as follows:

III. To the contents of the casserole, after boiling the material with nitric and sulphuric acids, add only seventy cc. of water, stir well to dissolve copper sulphate, then add rapidly an excess of ammonia (thirty cc. is generally sufficient), filter on a fifteen $\mathrm{cm}$. filter, and wash twice with ten cc. of dilute ammonia (one part ammonia to ten of water). By means of a rod, and fifty cc. of water measured into a small wash bottle, transfer the precipitate as completely as possible to the casserole without damaging the paper. Add, drop by drop, enough sulphuric acid to just redissolve the iron or alumina, then follow with twenty to twenty-five cc. of ammonia (sp. gr. 0.9), or sufficient to precipitate the oxides again and cause the liquid to smell strongly. Filter and wash with dilute ammonia as usual. After stoppering and shaking the bottles the colors may be read within 0.03 per cent. by placing the bottle close to one of the standards against a window pane and placing a piece of perfectly white, unruled paper behind them. ${ }^{1}$ Three bottles should never be placed closely together, as the middle one will appear too light.

A table of experiments is appended which shows the effects of variations in the working conditions. The battery assays are those of the same solutions whose color readings are given in the adjoining column, and since there are no impurities in the products tested to interfere with a battery assay, electrolysis furnishes an accurate estimation of the true amount of copper in solution and in the iron and aluminum precipitates which were dissolved in dilute sulphuric acid and electrolyzed. Most of the filtration, etc., was made by an assistant. $\quad A=$ Chemist, $B=$ Assistant Chemist.

1 Copper assaying on Lake Superior: Eng. and Min. J., April 20, 1895, p. 369. 


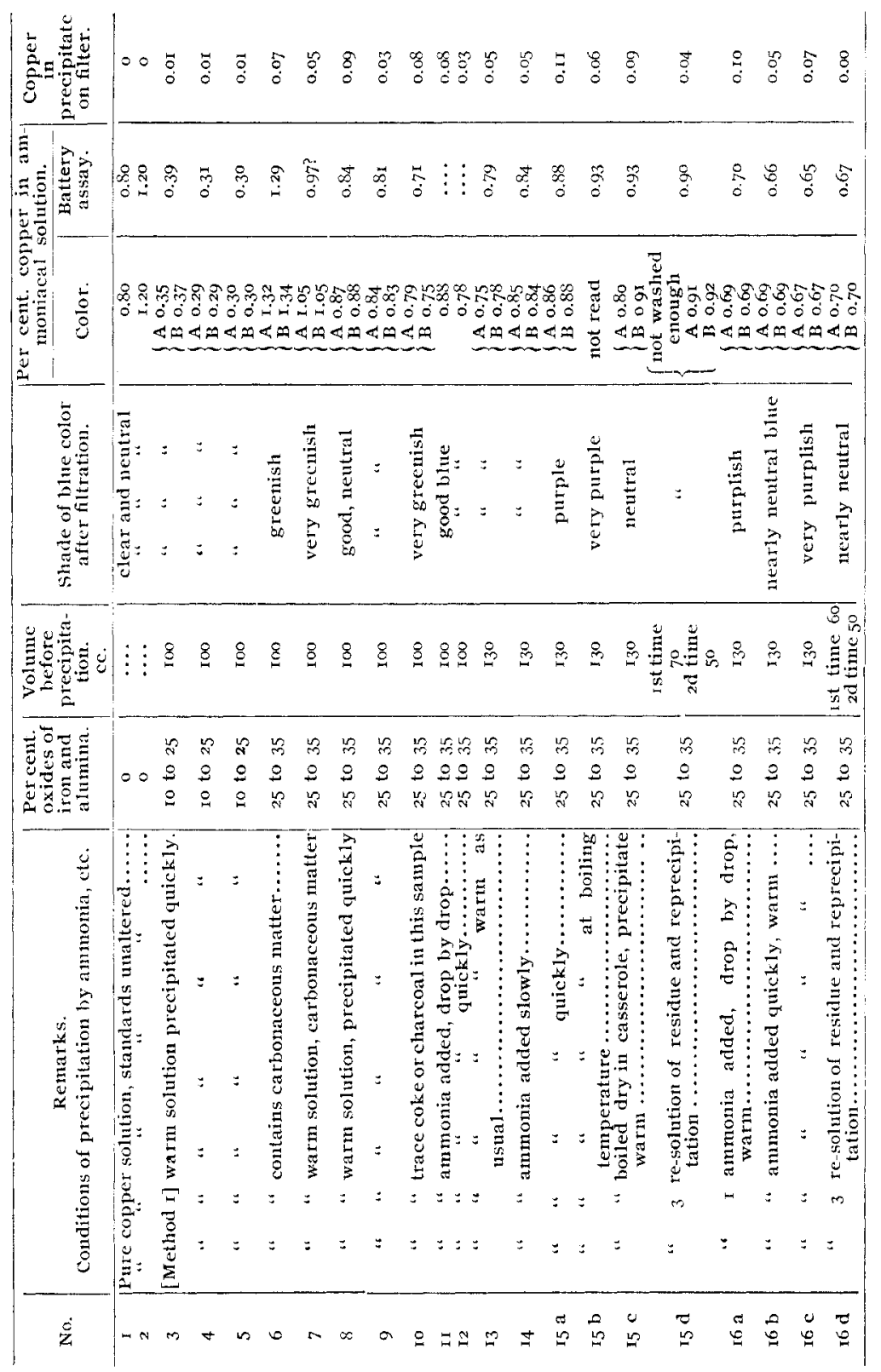


In the experiments with the approximate working test, the colors were read without any attempt to dilute to an exact match with the next lower standard, but the difference between the assay and the next lower and higher bottles was estimated by the eye, which, with practice, can be done within 0.03 per cent.

The tests marked "purplish" were not read until the shade (or tint) was corrected to that of the standards by the addition of a few cc. of ammonia.

If the first residue be boiled too dry, or the color be very purple after filtration, it will generally prove that the separation of copper from basic oxides by one precipitation with ammonia is very incomplete.

If the color be greenish there is a general tendency to read the colors a little too high, but the difference is generally slight and entirely within the limits of error in sampling. If the greenish tint be very pronounced the assay should be repeated, and if the trouble be due to the cupriferous material, the portion weighed for analysis should be kept for several minutes in a porcelain crucible at a full red heat and stirred with a platinum wire.

The writer recommends the general methods here given, in preference to those already in print, for reasons which have been specified, and considers modification No. 3 a better technical method than any one involving reduction of copper by aluminum for the following reasons:

$a$. A second precipitation of oxides of iron and aluminum will remove all but a trace of copper, if the washing be carefully completed, even when the material is rich in basic oxides.

b. No extra time is required for the second precipitation, since this dispenses with part of the necessary washing.

c. There is always a possible danger of incomplete reduction of copper by aluminum or of retention by the silica of a little copper (which would be extracted by ammonia), and more time is required, especially if the silica be removed by filtration before reduction with aluminum. 